\title{
Comparing the body mass index, blood pressure and blood biochemical changes during Ramadan between high to moderate level and low level physical activity groups prior to Ramadan among overweight and obese working women
}

\author{
Suriani Ismail $^{1}$, Khadijah Shamsuddin ${ }^{2}$, Khalib Abdul Latiff ${ }^{1}$, Hazizi Abu Saad $^{3}$
}

\begin{abstract}
${ }^{1}$ Department of Community Health, ${ }^{3}$ Department of Nutrition \& Dietetics, Faculty of Medicine and Health Sciences, Universiti Putra Malaysia, Serdang, Malaysia

${ }^{2}$ Department of Community Health, Faculty of Medicine, Universiti Kebangsaan Malaysia, Cheras, Malaysia
\end{abstract}

\section{Received: 19 May 2016}

Revised: 12 June 2016

Accepted: 13 June 2016

\author{
*Correspondence: \\ Dr. Suriani Ismail, \\ E-mail: si_suriani@upm.edu.my
}

Copyright: (C) the author(s), publisher and licensee Medip Academy. This is an open-access article distributed under the terms of the Creative Commons Attribution Non-Commercial License, which permits unrestricted non-commercial use, distribution, and reproduction in any medium, provided the original work is properly cited.

\begin{abstract}
Background: Physical inactivity and sedentary lifestyle are among the most certain causes of overweight and obesity and vice versa, increased physical activity is among the most certain means to reduce body weight in most overweight and obese cases. The objective of the study was to compare the blood pressure, blood lipid profile (i.e. total cholesterol (TC), high density lipoprotein (HDL-C), low density lipoprotein (LDL-C)) and triglyceride (TG) and fasting blood sugar (FBS) changes during Ramadan between those with 'high to moderate level' of physical activity and those with 'low physical activity' before Ramadan.

Methods: This was a prospective cohort study carried out during Ramadan. The respondent's level of physical activity prior to Ramadan was determined by using the metabolic equivalent score (METs) calculated by using the international physical activity questionnaire (IPAQ). METs score $>600$ were categorized as 'high to moderate level' while METs score $\leq 600$ as 'low level' physical activity. BMI, blood pressure and blood biochemical levels were measured before and during Ramadan.

Results: 140 respondents were recruited and 57.14\% were in the 'high to moderate level' physical activity group. At baseline systolic and diastolic pressure, TC, LDL-C, TG, FBS, TC/HDL-C ratio was lower but HDL-C was higher in the 'high to moderate level' physical activity group. During Ramadan, HDL-C reduced and TC/HDL-C ratio increased significantly in both groups $(\mathrm{P}<0.01)$, TG reduced significantly only in the 'high to moderate level' physical activity group $(\mathrm{P}=0.02)$ while FBS reduced significantly only in the 'low level' physical activity group ( $\mathrm{P}=0.04)$. Comparing changes between the two groups showed no significant difference.

Conclusions: The positive blood biochemical changes during Ramadan were more prominent in the group who were more physically active prior to Ramadan.
\end{abstract}

Keywords: Level of physical activity, Blood lipid profile changes, Ramadan

\section{INTRODUCTION}

Physical inactivity and sedentary lifestyle are among the most certain causes of overweight and obesity and vice versa, increased physical activity is among the most certain means to reduce body weight in most overweight and obese cases. ${ }^{1,2}$ Physical activity and inactivity is found to be associated with socio-demographic and socioeconomic factors. A study in Malaysia showed that 
age, marital status, income, education level and employment status were all significant factors associated with participation in physical activity. ${ }^{3,4}$ For example a study among Malaysian adults showed that the percentage of those who were physically active was twice among men $(40.0 \%)$ than women $(22.3 \%)$, highest among the age group of between 18-18 years (39.6\%) and lowest among the 30-39 age group (28.3\%), highest among the Chinese $(18.4 \%)$ and lowest in Malays $(4.9 \%) .^{5}$ It also reports that the time spent for recreational activities and involvement in sports were less among working men and women compared to those who were non-working (21.5\% versus $50.0 \%$ for men, $18.5 \%$ versus $21.7 \%$ for women). ${ }^{5}$

Physical activity is also known to influence blood pressure and blood biochemistry such as the level of total cholesterol (TC), high density lipoprotein (HDL-C), low density lipoprotein (LDL-C)) and triglyceride (TG) and fasting blood sugar (FBS). Studies show that physical activity such as exercise is negatively associated with blood pressure, independent of body mass index (BMI) and cardio respiratory fitness. ${ }^{6}$ As for the influence of physical activity on blood biochemistry, studies have showed that TC, LDL-C, TG decreases, while HDL-C increases with physical exercise. ${ }^{7}$ There were also studies which showed that physical exercise lowers the blood sugar. $^{8}$

During Ramadan, it is assumed that the level of physical activity decreases for most people. A study conducted to look at the level of activity undertaken by a group of Malay Muslim staff in a university in Malaysia before, during and after Ramadan showed that the physical activity (measured by number of steps per day) were lowest during Ramadan and comparison between genders showed that it was lower among the females. ${ }^{9}$ Therefore, although studies have shown that Ramadan fasting causes positive blood changes in both groups who were physically active and those who were not physically active during Ramadan. ${ }^{10}$ It will be beneficial to observe and to compare the changes between different levels of physical activeness prior to Ramadan.

The objective of the study were to examine the changes in blood pressure and blood biochemistry during Ramadan among a group of overweight and obese women working in public services and to compare these changes between those who were before Ramadan categorized into 'high to moderate level' physical activity group with those in 'low level' group.

\section{METHODS}

\section{Study design and study population}

This was a prospective cohort study. Respondents were Malay Muslim women working at four randomly selected public offices in two states in Malaysia (i.e., Putrajaya and Negeri Sembilan). The main inclusion criteria were overweight or obese (i.e. BMI $\geq 25 \mathrm{~kg} / \mathrm{m}^{2}$ ) and the exclusion criteria were if respondents were unable to fast in Ramadan or were pregnant.

\section{Data collection}

Socio-demographic and socioeconomic characteristic were collected using a structured self-administered questionnaire. The level of physical activity was determined using the structured self-administered International Physical Activity Questionnaire (IPAQ). The metabolic equivalent (MET) score was calculated and then respondents were categorized into 2 categories. Those with METs $\geq 600$ were 'moderate to high' physical activity and METs <600 were 'low level' physical activity. The body mass index (BMI) was calculated by measuring the height and the weight of the respondents. Blood for biochemistry (i.e., total cholesterol (TC), high density lipoprotein (HDL-C), low density lipoprotein (LDL-C), Triglyceride (TG) and fasting blood sugar (FBS) values) were measured from fasting venous blood taken before and during Ramadan. BMI, TC, HDL-C, LDL-C, TG and FBS were measured twice i.e. before and during Ramadan in year 2011.

\section{Data analysis}

Data was analysed using IBM SPSS Statistical software version 20. Chi squared and independent $t$ tests were used to compare respondents' characteristics at baseline, paired $t$ test was used to compare changes within groups and repeated measure ANOVA test to compare changes between groups. Significance level was set at $\mathrm{P}<0.05$.

\section{Ethical approval}

This study was approved by the institutional Research and Ethics Committee and written consent was obtained from each respondent and has observed Helsinki Declaration's principles.

\section{RESULTS}

A total of 140 respondents were recruited. Among them $57.14 \%$ (80 respondents) were categorized into 'moderate to high level' of physical activity and $42.86 \% \quad(60$ respondents) in 'low level' physical activity groups. Table 1 and Table 2 show the comparison of the respondents' characteristics at baseline between 'moderate to high level' and 'low level' of physical activity groups, while Table 3 shows comparison of the changes during Ramadan within and also between groups.

\section{Comparison of socio-demographic and socioeconomic characteristics, level of physical activity, BMI, blood pressure and blood biochemical at baseline}

At baseline the socio-demographic and socioeconomic characteristics of respondents in both groups were 
comparable except that there was a significant difference for the variable 'employment position'. The percentage of those in 'high to moderate physical activity' were higher in the clerical category compared to managerial positions (63.8\% versuss $37.1 \%), \mathrm{P}<0.01$. At baseline, the mean BMI was in the obese category (i.e. $\geq 30 \mathrm{~kg} / \mathrm{m}^{2}$ ) for both groups. The mean blood pressure, TC, LDL-C, TG and FBS were within normal range in both groups. However, the mean HDL-C was very low $(<1.68 \mathrm{mmol} / \mathrm{l})$ and the
TC/HDL-C ratio was in the high risk category (i.e. $\geq 4.0$ ) in both groups. At baseline, the BMI, diastolic pressure, TC, LDL-C, TG, FBS and TC/HDL-C ratio were lower in the 'high to moderate' level physical activity group, however the differences was not statistically significant except for TG $(\mathrm{P}=0.03)$. The HDL-C was slightly higher in the group with 'high to moderate physical activity' but the difference was also not statistically significant.

Table 1: Socio-demographic and socioeconomic characteristic of the respondents according to level of physical activity $(n=140)$.

\begin{tabular}{|c|c|c|c|c|}
\hline \multirow{4}{*}{ Variable } & \multicolumn{4}{|c|}{ Level of physical activity } \\
\hline & \multirow{3}{*}{$\begin{array}{l}\text { Moderate to high } \\
(\mathrm{n}=80) \\
\mathrm{n}(\%)\end{array}$} & \multicolumn{3}{|l|}{ Low } \\
\hline & & $(\mathrm{n}=60)$ & \multirow[b]{2}{*}{$\chi^{2}$} & \multirow{2}{*}{$P$ value } \\
\hline & & $\mathrm{n}(\%)$ & & \\
\hline \multicolumn{5}{|l|}{ Age } \\
\hline$>40$ & $32(54.2)$ & $27(45.8)$ & 0.35 & 0.55 \\
\hline$\leq 40$ & $48(59.3)$ & $33(40.7)$ & & \\
\hline \multicolumn{5}{|l|}{$\overline{\text { Marital status }}$} \\
\hline Married & $67(58.8)$ & 47 (41.2) & 0.67 & 0.42 \\
\hline Single & $13(50.0)$ & $13(50.0)$ & & \\
\hline \multicolumn{5}{|l|}{ Children } \\
\hline Yes & $60(58.8)$ & $42(41.2)$ & 0.43 & 0.51 \\
\hline No & $20(52.6)$ & $18(47.4)$ & & \\
\hline \multicolumn{5}{|l|}{ Education level } \\
\hline Tertiary education & $24(51.1)$ & $23(48.9)$ & 1.06 & 0.30 \\
\hline High school & $56(60.2)$ & $37(39.8)$ & & \\
\hline \multicolumn{5}{|c|}{ Employment position } \\
\hline Managerial & $13(37.1)$ & $22(62.9)$ & 7.62 & $<0.01 *$ \\
\hline Clerical & $67(63.8)$ & $38(36.2)$ & & \\
\hline \multicolumn{5}{|l|}{ Household income } \\
\hline$>2500$ & $47(56.0)$ & $37(44.0)$ & 0.12 & 0.73 \\
\hline$<2500$ & $33(58.9)$ & $23(41.1)$ & & \\
\hline
\end{tabular}

${ }^{\mathrm{a} C h i}$ squared test, significant $\mathrm{P}<0.05$.

Table 2: Comparing BMI, systolic and diastolic pressure, blood biochemical (TC, HDL-C, LDL-C, TG and FBS) and TC/HDL-C ratio at baseline (before Ramadan) between 'moderate to high' level physical activity and 'low level' physical activity groups $(\mathrm{N}=140)$.

\begin{tabular}{|c|c|c|c|c|}
\hline \multirow{3}{*}{ Variable } & \multicolumn{4}{|c|}{ Level of physical activity } \\
\hline & $\begin{array}{l}\text { Moderate to high } \\
(n=80)\end{array}$ & $\begin{array}{l}\text { Low } \\
(n=60)\end{array}$ & & \multirow[t]{2}{*}{$P$ value $^{\mathrm{a}}$} \\
\hline & Mean (SD) & Mean (SD) & $t$ & \\
\hline BMI $\left(\mathrm{kg} / \mathrm{m}^{2}\right)$ & $30.77(4.21)$ & $31.52(4.10)$ & 1.06 & 0.29 \\
\hline Systolic pressure (mmHg) & $123.64(17.36)$ & $124.67(14.17)$ & 0.38 & 0.71 \\
\hline Diastolic pressure $(\mathrm{mmHg})$ & $76.75(9.26)$ & $79.07(11.45)$ & 1.32 & 0.18 \\
\hline $\mathrm{TC}(\mathrm{mmol} / \mathrm{l})$ & $4.61(1.16)$ & $5.00(1.12)$ & 2.00 & $0.05 *$ \\
\hline HDL-C (mmol/l) & $1.06(0.41)$ & $1.04(0.39)$ & 0.44 & 0.66 \\
\hline LDL-C (mmol/l) & $2.47(0.71)$ & $2.57(0.70)$ & 0.92 & 0.36 \\
\hline $\mathrm{TG}(\mathrm{mmol} / \mathrm{l})$ & $0.96(0.40)$ & $1.13(0.50)$ & 2.23 & 0.03* \\
\hline FBS (mmol/l) & $4.52(1.03)$ & $4.70(0.98)$ & 1.00 & 0.32 \\
\hline TC/HDL-C & $4.82(1.82)$ & $5.48(2.27)$ & 1.90 & 0.06 \\
\hline
\end{tabular}

independent $\mathrm{t}$ test, significant $\mathrm{P}<0.05$. 
Comparison of BMI, blood pressure and blood biochemical changes during Ramadan

Table 3 shows the changes during Ramadan. The BMI and HDL-C were significantly reduced while the TC/HDL-C ratio was significantly increased in both groups $(P<0.01)$. However, the reduction of TG was only significant in the 'moderate to high' level physical activity group $(P=0.02)$ and the reduction of FBS was only significant in the 'low level' physical activity group prior to Ramadan. $(P=0.04)$. Comparing changes (BMI, systolic and diastolic blood pressure, TC, HDL-C, LDLC, TG, FBS and TC/HDL-C ratio) between the two groups adjusted to BMI showed no significant difference.

Table 3: Comparing BMI, systolic and diastolic pressure, blood biochemical (TC, HDL-C, LDL-C, TG and FBS) and TC/HDL-C ratio changes during Ramadan within and between 'moderate to high' level physical activity and 'low level' physical activity groups $(\mathrm{N}=140)$.

\begin{tabular}{|c|c|c|c|c|c|c|}
\hline & \multicolumn{4}{|l|}{ Within groups } & \multirow{3}{*}{\multicolumn{2}{|c|}{ Between groups }} \\
\hline & \multicolumn{4}{|c|}{ Level of physical activity } & & \\
\hline & \multicolumn{2}{|l|}{$\begin{array}{l}\text { Moderate to high } \\
(\mathrm{n}=80)\end{array}$} & \multicolumn{2}{|l|}{$\begin{array}{l}\text { Low } \\
(n=60)\end{array}$} & & \\
\hline & Mean (SD) & $P$ value $^{\mathrm{a}}$ & Mean (SD) & $P$ value $^{\mathrm{a}}$ & F Stat (df) & $P$ value $^{\mathrm{b}}$ \\
\hline \multicolumn{7}{|l|}{ BMI $\left(\mathrm{kg} / \mathrm{m}^{2}\right)$} \\
\hline Before Ramadan & $30.77(4.21)$ & $<0.01$ & $31.51(4.10)$ & $<0.01$ & & \\
\hline During Ramadan & $30.07(4.34)$ & & $30.65(4.04)$ & & $1.98(1)$ & 0.96 \\
\hline \multicolumn{7}{|l|}{ Systolic (mmhg) } \\
\hline Before Ramadan & $123.64(17.36)$ & 0.44 & $124.67(14.17)$ & 0.41 & & \\
\hline During Ramadan & $122.80(15.28)$ & & $123.58(14.35)$ & & $0.00(1)$ & 0.34 \\
\hline \multicolumn{7}{|l|}{ Diastolic (mmhg) } \\
\hline Before Ramadan & $76.75(9.26)$ & 0.40 & $79.07(11.45)$ & 0.33 & & \\
\hline During Ramadan & $76.10(8.79)$ & & $77.87(9.17)$ & & $0.07(1)$ & 0.79 \\
\hline \multicolumn{7}{|l|}{ TC (mmol/l) } \\
\hline Before Ramadan & $4.61(1.17)$ & 0.34 & $5.00(1.12)$ & 0.65 & & \\
\hline During Ramadan & $4.49(1.08)$ & & $4.94(0.92)$ & & $0.11(1)$ & 0.73 \\
\hline \multicolumn{7}{|l|}{ HDL-C (mmol/l) } \\
\hline Before Ramadan & $1.07(0.41)$ & $<0.01$ & $1.04(0.39)$ & $<0.01$ & & \\
\hline During Ramadan & $0.82(0.24)$ & & $0.88(0.33)$ & & $1.86(1)$ & 0.17 \\
\hline \multicolumn{7}{|l|}{ LDL-C (mmol/l) } \\
\hline Before Ramadan & $2.47(0.72)$ & 0.12 & $2.58(0.70)$ & 0.28 & & \\
\hline During Ramadan & $2.35(0.70)$ & & $2.67(0.65)$ & & $3.54(1)$ & 0.06 \\
\hline \multicolumn{7}{|l|}{ TG (mmol/l) } \\
\hline Before Ramadan & $0.96(0.40)$ & 0.02 & $1.13(0.50)$ & 0.37 & & \\
\hline During Ramadan & $0.87(0.34)$ & & $1.09(0.50)$ & & $0.75(1)$ & 0.39 \\
\hline \multicolumn{7}{|l|}{ FBS (mmol/l) } \\
\hline Before Ramadan & $4.52(1.03)$ & 0.32 & $4.70(0.98)$ & 0.04 & & \\
\hline During Ramadan & $4.42(0.84)$ & & $4.47(0.66)$ & & $0.47(1)$ & 0.49 \\
\hline \multicolumn{7}{|l|}{ TC/HDL-C } \\
\hline Before Ramadan & $4.83(1.82)$ & $<0.01$ & $5.48(2.27)$ & $<0.01$ & & \\
\hline During Ramadan & $5.73(1.58)$ & & $6.23(2.11)$ & & $0.34(1)$ & 0.56 \\
\hline
\end{tabular}

(1) Baseline/Before Ramadan; ${ }^{a}$ paired t test and ${ }^{\mathrm{b}}$ repeated measure ANOVA, significant $\mathrm{P}<0.05$.

\section{DISCUSSION}

The respondents in this study were a group of overweight and obese Malay Muslim women working in the public sector. The percentage of respondents in 'high to moderate level' physical activity before Ramadan in this study was $57.14 \%$. This percentage was low compared to a study among working women from all ethnic groups (regardless of body weight) in private sectors in an urban district in Selangor which was $71.1 \%{ }^{4}$ Nevertheless, these two studies are not comparable due to the different respondents' characteristics. The percentage of those in 'high to moderate level' physical activity group in this study was significantly higher in the clerical group compared to the managerial group (63.8 and $37.1 \%$, $\mathrm{P}<0.01$ ). The different percentages (in the managerial compared to clerical group) could be due to the different nature of work. 
Although at baseline the mean blood pressure was within normal range for both groups, the systolic and diastolic blood pressures were lower in the 'high to moderate level' than the 'low level' physical activity group. Even though, the difference is not statistically significant but these observations could be because low habitual energy expenditure is closely related with increased blood pressure. ${ }^{6}$ At baseline, the HDL-C was low in both groups. The low HDL-C level was expected as respondents were among those who are overweight and obese and studies have shown that HDL-C has an inverse correlation with BMI. ${ }^{11,12}$ Studies have shown that those with higher level of physical activity would have lower TC, LDL-C, TG and FBS, but higher HDL-C, however in this study the only significant differences between the two groups at baseline was for TG (i.e. TG was significantly lower in the 'high to moderate level' physical activity group compared to 'low level' physical activity group). ${ }^{7,12}$ Therefore, although HDL-C was already lower than normal range in both groups, but it was even lower in the 'low level' physical activity group. Thus at baseline TC/HDL-C ratio was high in both group and comparing TC/HDL-C between groups showed that it was lower in the group with 'high to moderate level' physical activity before Ramadan than the group who were not. This is also an expected observation because physical activeness is inversely related to TC/HDL-C (and is associated with less cardiovascular risk). ${ }^{13}$

In this study, during Ramadan the BMI was significantly reduced in both groups. This is an expected result as most studies regarding BMI changes in Ramadan have shown significant reduction. ${ }^{14,15}$ The systolic and diastolic pressures in both groups had reduced too. Although the reduction was not statistically significant, this is also expected as BMI and blood pressure has an established linear association. ${ }^{16,17}$ The reduced BMI during Ramadan could also influence changes in the blood biochemistry. In general, reduced BMI is associated with reduced TC, LDL-C, TG and FBS but increased HDL-C. ${ }^{11,12}$ However in this study, despite there being a significant reduction of BMI in both groups, only TG was significantly reduced in the 'high to moderate level' physical activity group and ironically HDL-C didn't increase but instead was significantly reduced in both groups. The reduced TG during Ramadan in both groups could be due to the reduction of $\mathrm{BMI}$ and the effect could be relatively higher in those who with 'high to moderate level' physical activity prior to Ramadan. Nevertheless, comparing TG changes between groups also showed no significant difference. $^{18,19}$

The significant reduction of HDL-C in both groups during Ramadan was an unusual finding, since many studies show that HDL-C has an inverse correlation with BMI. ${ }^{11,12}$ The opposite changes in this study were as if the inverse relationship was lost. The possible explanation could be explained by a study which showed the linear relationship in the regression model of BMI and HDL-C associations was lost at high BMI values. ${ }^{20}$
Therefore, since the respondents in this study were among those who were overweight and obese, the observed result could be due to the loss of this inverse relationship. In addition, there might be reduced physical activity during Ramadan which in general is associated with reduced HDL-C. ${ }^{7,9}$ Thus, reduced physical activity during Ramadan could also contribute to the reduction HDL-C among the respondents during Ramadan in this study. However, comparing HDL-C changes between groups showed no significant difference. At baseline the TC/HDL-C ratio was in the high cardiovascular risk category, for both groups and this observation was expected as all respondents were either overweight or obese. ${ }^{21}$ However, during Ramadan despite significant $\mathrm{BMI}$ reduction, the $\mathrm{TC} / \mathrm{HDL}-\mathrm{C}$ ratio increased significantly in both groups although comparing between groups showed no significant difference. The TC/HDL-C changes had resulted from the changes in TC and HDL$\mathrm{C}$, which was due to the combined consequences of BMI and physical activeness before and during Ramadan in both groups.

As for the FBS, during Ramadan, it decreased in both groups with a significant decrease only in the 'low level' physical activity group before Ramadan. The FBS reduction during Ramadan was expected as shown in many similar studies observing blood changes in Ramadan. $^{22,23}$ The reduction could be due to the decreased food quantity consumed during Ramadan, especially from the carbohydrate food group. ${ }^{22,24}$ However, physical activity or physical exercise can positively influence blood sugar i.e., when physical activity was reduced (assuming it happens during Ramadan), FBS was expected to increase. ${ }^{8,25}$ Therefore, to some extent the reduced FBS (due to reduced food quantity during Ramadan) was cancelled by the reduction in physical activity and since the effect of shift of physical activeness was more in those who with 'high to moderate physical activity' before Ramadan, their FBS reduction was not statistically significant compared to a significant reduction observed in the group who were not physically active before Ramadan.

\section{Limitation and strength}

The Ramadan blood biochemical changes among overweight and obese woman can't be explained by a reduction in BMI and reduced physical activeness alone, because there were many confounding factors which might take place during Ramadan such as changes in diet and sleeping hours which were not controlled in this study. The effect of Ramadan fasting alone in a normal weight respondent regardless of their level of physical activity before Ramadan could be different as many studies show that in normal weight adults, Ramadan fasting can significantly increase HDL-C and reduce LDL-C. $^{22-24}$ In fact some other studies reported that the increase of HDL-C was up to about 20-30\% and LDL-C decrease was up to $20 \%{ }^{26,27}$ Nevertheless, there were many studies that showed increased physical activity 
during Ramadan bring about positive blood biochemistry changes which would encourage physical activity during Ramadan and in this prospective observations among a group of working women who were overweight points out that increasing levels of physical activity before Ramadan could also result in positive blood biochemistry changes. $^{26-28}$

\section{CONCLUSION}

To conclude, although not statistically significant, in this study the health benefits of physical activeness were observed in the group with 'high to moderate level' physical activity before Ramadan (e.g., lower BMI, diastolic and diastolic blood pressure, TC, LDL-C, TG, FBS, TC/HDL-C but higher HDL-C than the 'low level' physically activity group). The indication of positive health outcome from reduced BMI during Ramadan such as reduced TG was more evident in the group with 'high to moderate level' physical activity prior to Ramadan while the indication of negative health outcome of reduced physical activity was evident in both groups (i.e., reduced HDL-C). On the other hand, the effect of Ramadan fasting in reducing FBS was more evident in the group that was not physically active prior to Ramadan. Higher level of physical activity prior to Ramadan could positively influence the blood biochemical changes in Ramadan. Muslims should be encouraged to increase the level of physical activity prior to Ramadan and ideally to maintain it during Ramadan.

\section{ACKNOWLEDGMENTS}

The authors wish to thank the Malaysian Health Promotion Board (through the Islamic Medical Association of Malaysia) and Universiti Kebangsaan Malaysia, who had funded the research. The article reflects findings from the research, and do not necessarily represent the official views of either sponsors.

Funding: Malaysian Health Promotion Board (through the Islamic Medical Association of Malaysia) and Universiti Kebangsaan Malaysia

Conflict of interest: None declared

Ethical approval: The study was approved by the Institutional Ethics Committee

\section{REFERENCES}

1. Pietiläinen KH, Kaprio J, Borg P, Plasqui G, YkiPietiläinen KH, Kaprio J, Borg P, Plasqui G, YkiJärvinen H, Kujala UM, et al. Physical inactivity and obesity: a vicious circle. Obesity. 2008;16(2):409-14.

2. Mustelin L, Silventoinen K, Pietiläinen K, Rissanen A, Kaprio J. Physical activity reduces the influence of genetic effects on BMI and waist circumference: a study in young adult twin. Int J Obes. 2009;33: 2936.
3. Cheah YK. The Determinants of participation in Physical Activity in Malaysia. Osong Public Health Res Perspect. 2014;5(1):20-7.

4. Affira SK, Mohd Nasir MT, Hazizi AS, Kandiah, M. Socio-demographic and psychosocial factors associated with physical activity of working woman in Petaling Jaya, Malaysia. Mal $\mathbf{J}$ of Nutr. 2011;17(3):315-24.

5. Poh BK, Safiah MY, Tahir A, Siti Haslinda MD, Siti Norazlin N, Norimah AK, Wan Manan W, et. al. Physical Activity Pattern and Energy Expenditure of Malaysian Adults: Findings from the Malaysian Adult Nutrition Survey (MANS). Mal J of Nutr. 2010;16(1):13-37.

6. Warenham NJ, Wong MY, Hennings S, Mitchell J, Rennie K. Quantifying the association between habitual energy expenditure and blood pressure. Int J Epidemiol. 2000;29:655-60.

7. Skoumas J, Pitsavos C, Panagiotakos DB, Chrysohoou C, Zeimbekis A, Papaioannou I, et al. (2003) Physical activity, high density lipoprotein cholesterol and other lipids levels, in men and women from ATTICA study. Lipid Health Dis. 2003;2(3):1-7.

8. Healy GN, Dunstan DW, Shaw JE, Zimmet PZ, Owen N. Beneficial associations of physical activity with 2-h but not fasting blood glucose in Australian adult. Diabetes Care. 2006;29(12):2598-604.

9. Soh KG, Aminuddin Y, Nur Surayyah MA, Soh KL, Ong SL. Comparing physical activity of Malaysian Malay Men and Women before, during and after Ramadan Pertanika. J Soc Sci \& Hum. 2013;21(2):569-78.

10. Reza SAH, Hejazi K. The effects of Ramadan fasting and physical activity on blood haematological-biochemical parameters. Iran J Basic Med Sci. 2013;16:845-9.

11. Schroder H, Marrugat J, Elosua R, Covas MI. Relationship between bodymass index, serum cholesterol, leisure time physical activity and diet in a Mediterannean South -European population. Br J Nutr. 2003;90(2):431-40.

12. Schubert CM, Rogers NL, Remsberg KE, Sun SS, Chumlea WC, Demerath EW, et al. (2006) Lipids, lipoproteins, lifestyle, adiposity and fat-free mass during middle age: the Fels Longitudinal Study. Int J Obes. 2006;30:251-60.

13. Twisk JW, Kemper HC, van Mechelen W. (2000) Tracking of activity and fitness and the relationship with cardiovascular disease risk factor. Med Sci Sports Exerc. 2000;32(8):1455-61.

14. Hajek P, Myers K, Dhanji AR, West O \& McRobbie H. Weight change during and after Ramadan fasting. J Public Health. 2011;34(3):377-81.

15. Khaled BM, Belbraouet S. Effect of Ramadan fasting on anthropometric parameters and food consumption in 276 type 2 diabetic obese women. Int J Diabetes Dev C. 2009;29(2):62-8.

16. Aucott L, Poobalan A, Smith WC, Avenell A, Jung $\mathrm{R}$, Broom J. Effects of weight loss in 
overweight/obese individuals and long-term hypertension outcomes: a systematic review. Hypertension. 2005;45(6):1035-41.

17. Tesfaye F, Nawi NG, Van Minh H, Byass P, Berhane Y, Bonita R, Wall S. Association between body mass index and blood pressure across three populations in Africa and Asia. J Hum Hypertens. 2007;21(1):28-37.

18. Al-Numair K. Body weight and some biochemical changes associated with Ramadan fasting in healthy Saudi. J Med Sci. 2006;6(1):112-6.

19. Barkia A, Mohamed K, Smaoui M, Zouari N, Hammami M, Nasri M. Change of diet, plasma lipids, lipoproteins, and fatty acids during Ramadan: a controversial association of the considered Ramadan model with atherosclerosis risk. JHealth Popul Nutr. 2011;29(5):486-93.

20. Sower MF, Sigler. Complex relationship between increasing fat mass and decreasing high density lipoprotein cholesterol levels: evidence from a population-based study of premenopausal women. Am Epidemiol. 1999;149(1):47-54.

21. Brenner DR, Tepyl K, Eny KM, Cahill LE, ElSohemy A. Comparison of body mass index and waist circumference as predictors of cardiometabolic health in a population of young Canadian adults. DiabetoMetab Syndr. 2010;2:28.

22. Mansi KMS. Study the Effect of Ramadan fasting on serum glucose and lipid profile among healthy Jordanian students. Am J Appl Sci. 2007;4(8):5659.

23. Ibrahim O, Kamaruddin N, Wahab N \& Rahman MM. Ramadan fasting and cardiac biomarker in patient with multiple cardiovascular disease risk factors. Int J Cardiovasc Res. 2010;7(2):1540-2592.

24. Saada AD, Attou SG, Belkacemi L, Chabane AO, Italhi M, Bekada AMA, Kati D. (2010). Effect of Ramadan fasting on glucose, glysated haemoglobin, insulin, lipids and proteinous concentrations in women with non-insulin dependent diabetes mellitus. African J of Biotechnology. 2010;9:87-94.

25. Momeni L. The comparison of one session graded exercise test effect on fasting blood sugar in trained and untrained woman. Intl Res J Appl Basic Sci. 2013;6(3):313-6.

26. Lamine F, Bouguerra, Jabrane J, Marrakchi Z, Ben Rayana MC, Ben Slama C, Gaigi S. Food intake and high density lipoprotein cholesterol levels changes during Ramadan fasting in healthy young subjects. La Tunisie Médicale. 2006;84(10):647-50.

27. Lamri-Senhadji MY, El Kebir B, Belleville J, Bouchenak M. Assessment of dietary consumption and time-course of changes in serum lipids and lipoproteins before, during and after Ramadan in young Algerian adults. Singapore Med J. 2009;50(3):288-94.

28. Haghdoost AA, Poorranjbar M. The interaction between physical activity and fasting on the serum lipid profile during Ramadan. Singapore Med J. 2009;50(9):897-901.

Cite this article as: Ismail $\mathrm{S}$, Shamsuddin $\mathrm{K}$, Latiff KA, Saad HA. Comparing the body mass index, blood pressure and blood biochemical changes during Ramadan between high to moderate level and low level physical activity groups prior to Ramadan among overweight and obese working women. Int $\mathbf{J}$ Community Med Public Health 2016;3:1877-83. 